\title{
Effect of Terminal Group Halogenation of Naphthalene-Based Nonfullerene Acceptors on Their Film Structure and Photophysical and Photovoltaic Properties
}

\begin{abstract}
Tomokazu Umeyama ${ }^{\text {a* }}$, Tatsuho Wada $^{\mathrm{b}}$, Kensho Igarashi ${ }^{\mathrm{b}}$, Kosaku Kato ${ }^{\mathrm{c}}$, Akira Yamakata ${ }^{\mathrm{c}}$, Taiki Takeyama $^{\mathrm{d}}$, Yuji Sakamoto ${ }^{\mathrm{d}}$, Yasunari Tamai ${ }^{\mathrm{d}, \mathrm{e}}$, Hideo Ohkita $^{\mathrm{d}}$, Keiichi Ishida ${ }^{\mathrm{b}}$, Tomoyuki Koganezawa ${ }^{\mathrm{f}}$, Shunsuke Ohtani ${ }^{\mathrm{d}}$, Kazuo Tanaka ${ }^{\mathrm{d}}$, and Hiroshi Imahori ${ }^{\mathrm{b}, \mathrm{g} *}$
\end{abstract}

${ }^{a}$ Department of Applied Chemistry, Graduate School of Engineering, University of Hyogo, 2167 Shosha, Himeji, Hyogo 671-2201, Japan.

${ }^{b}$ Department of Molecular Engineering, Graduate School of Engineering, Kyoto University, Nishikyo-ku, Kyoto 615-8510, Japan.E-mail: imahori@scl.kyoto-u.ac.jp

${ }^{c}$ Photochemical Reaction Laboratory, Graduate School of Engineering, Toyota Technological Institute, Nagoya 468-8511, Japan.

${ }^{d}$ Department of Polymer Chemistry, Graduate School of Engineering, Kyoto University, Nishikyoku, Kyoto 615-8510, Japan.

e Japan Science and Technology Agency (JST), PRESTO, 4-1-8 Honcho Kawaguchi, Saitama 3320012, Japan

${ }^{f}$ Japan Synchrotron Radiation Research Institute, 1-1-1, Kouto, Sayo-cho, Sayo-gun, Hyogo 6795198, Japan

${ }^{g}$ Institute for Integrated Cell-Material Sciences (WPI-iCeMS), Kyoto University, Sakyo-ku, Kyoto 606-8501, Japan

E-mail: umeyama@eng.u-hyogo.ac.jp,imahori@scl.kyoto-u.ac.jp 


\section{Experimental}

Instruments. ${ }^{1} \mathrm{H}$ NMR and ${ }^{13} \mathrm{C}$ NMR spectra were measured with a JEOL JNM-EX400 NMR spectrometer. High-resolution mass spectra were measured on a Thermo Fisher Scientific EXACTIVE (APCI) and LTQ orbitrp XL (MALDI). Attenuated total reflectance (ATR) FT-IR spectra were recorded on a ThermoFisher Scientific Nicolet 6700 FT-IR. Thermogravimetric analysis (TGA) measurements were conducted with a SHIMADZU TG-60 under flowing nitrogen at a scan rate of $10^{\circ} \mathrm{C} \mathrm{min}^{-1}$. Differential scanning calorimetry (DSC) analysis was made on a SHIMADZU DSC-60 at a scan rate of $10{ }^{\circ} \mathrm{C} \mathrm{min}^{-1}$. UV-vis-near infrared (NIR) absorption spectra were obtained on a Perkin Elmer Lambda 900UV/vis/NIR spectrometer. Steady-state fluorescence spectra were recorded on a HORIBA NanoLog spectrofluorometer. Cyclic voltammetry (CV) measurements were performed in a deoxygenated solution of tetra- $n$-butylammonium hexafluorophosphate $(0.1 \mathrm{M})$ in $\mathrm{CH}_{3} \mathrm{CN}$ using an ALS 630A electrochemical analyzer, a glassy-carbon working electrode coated with sample films, a platinum-wire auxiliary electrode, and $\mathrm{Ag} / \mathrm{AgNO}$ as a reference electrode. Absolute photoluminescence quantum efficiencies were determined using a HAMAMATSU PHOTONICS Quantaurus-QY Plus Absolute PL quantum yield spectrometer C13534-01. Atomic force microscopy (AFM) analyses were carried out with an Asylum Technology MFP-3D-SA in the AC mode.

Photoemission yield spectroscopy in air (PYSA) measurements were performed using AC-3 (Riken Keiki). Specimens were prepared by spin-coating the NFA solutions onto glass substrates. UV photons emitted from a deuterium lamp were monochromatized by a grating spectrometer and focused on a sample film. Once the photon energy exceeds the ionization energy (i.e., the HOMO energy) of the sample substance, photoemission occurs. Photoelectrons emitted from the sample were counted by an open counter. Then, the square root of the photoelectron count was plotted against the photon energy. The threshold energy corresponds to the energy required to remove just one electron from the surface of the sample film, and can be interpreted as the HOMO energy level.

Photocurrent-voltage characteristics were measured with Keithley 2400 SourceMeter under a nitrogen atmosphere and simulated solar light (100 $\mathrm{mW} \mathrm{cm}^{-2}$, AM1.5) with OTENTO-SUN III solar simulator (Bunkoukeiki). Photocurrent action spectra were recorded with CEP-2000RR 
(Bunkoukeiki). Current-voltage characteristics of the electron- and hole-only devices for space charge-limited current (SCLC) measurements were conducted using Keithley 2400 SourceMeter under a nitrogen atmosphere.

Theoretical Calculations. Geometry optimization and electronic structure calculations were performed using density functional theory (DFT) at the RB3LYP/6-31G(d) level in chloroform polarizable continuum model (PCM). Calculations were carried out using the Gaussian 09 program. ${ }^{1}$ All structures were fully optimized without any symmetry restriction.

Time-resolved Photoluminescence. The samples were excited at the absorption maxima with femtosecond pulses (90 fs duration, $210 \mu \mathrm{J} \mathrm{cm}^{-2}$ pulse $^{-1}$ ) from a femtosecond Ti:sapphire laser system (Spectra-Physics, Solstice \& TOPAS Prime; $1 \mathrm{kHz}$ repetition rate). The emitted light was collected by an off-axis parabolic mirror, dispersed in wavelength with a polychromator, and then detected by a streak camera (Hamamatsu, C14831-130). The time resolution was ca. 30 ps. The photoluminescence decays were almost identical when the excitation intensity was reduced to half.

Femtosecond Transient Absorption. Femtosecond transient absorption data were collected with a pump and probe femtosecond transient spectroscopy system. This system consists of a regenerative amplified Ti:sapphire laser (Spectra-Physics, Hurricane) and a transient absorption spectrometer (Ultrafast systems, Helios). The amplified Ti:sapphire laser provided $800 \mathrm{~nm}$ fundamental pulses at a repetition rate of $1 \mathrm{kHz}$ with an energy of $0.8 \mathrm{~mJ}$ and a pulse width of $100 \mathrm{fs}$ (full-width at halfmaximum), which were split into two optical beams with a beam splitter to generate pump and probe pulses. One fundamental beam was converted into white-light pulses employed as probe pulses in the wavelength region from 800 to $1400 \mathrm{~nm}$. The other fundamental beam was used as pump pulses at $700 \mathrm{~nm}$ after conversion with an ultrafast optical parametric amplifier (Spectra-Physics, TOPAS). The pump pulses were modulated mechanically at a repetition rate of $500 \mathrm{~Hz}$. Temporal evolution of the probe intensity was recorded with an InGaAs linear diode array sensor (Ultrafast Systems, SPEC- 
NIR). Transient absorption spectra and decays were collected over the time range of -5 ps to $3 \mathrm{~ns}$. Typically, 2500 laser shots were averaged at each delay time to obtain a detectable absorbance change as small as $\sim 10^{-4}$. To cancel out orientation effects on the dynamics, the polarization direction of the linearly polarized probe pulse was set at the magic angle of $54.7^{\circ}$ with respect to that of the pump pulse. The sample films were encapsulated in a nitrogen-filled glove box. Note that the transient absorption spectra and dynamics were highly reproducible even after several measurements. In other words, the laser irradiation had negligible effects on the sample degradation at least under those experimental conditions.

Microsecond Transient Absorption. The microsecond transient absorption data were collected using a sensitive microsecond transient absorption system. A Nd:YAG laser (Elforlight, SPOT-10200-532) operating at a wavelength of $532 \mathrm{~nm}$ was used as the excitation source. White light from a tungsten lamp with a stabilized power source was used as the probe light. Two monochromators and appropriate optical cut-off filters were placed before and after the sample to increase the signal-tonoise ratio.

SCLC Measurements. The hole and electron mobilities were measured using the SCLC method by using devices with the configurations of ITO/PEDOT:PSS/polymer:NFA/MoO$/ \mathrm{Au}$ for hole and ITO/ZnO/NFA/Al or ITO/ZnO/polymer:NFA/Al for electron by taking current-voltage curves and fitting the results to a space charge limited form, where the SCLC is described by:

$$
J=9 \varepsilon_{0} \varepsilon_{\mathrm{r}} \mu V^{2} / 8 L^{3}
$$

where $\varepsilon_{0}$ is the permittivity of free space, $\varepsilon_{\mathrm{r}}$ is the dielectric constant of the polymer, $\mu$ is the charge mobility, $V$ is the voltage drop across the device, and $L$ is the thickness of the blend film. The dielectric constant $\varepsilon_{\mathrm{r}}$ is assumed to be 3 , which is a typical value for organic semiconductors.

GIWAXS Measurements. Samples were prepared by spin-coating the NFA, polymer, or polymer:NFA solution on the ITO/ZnO substrate as conducted in the OPV device fabrications. 
GIWAXS measurements were conducted at the SPring-8 on beamline BL46XU. The sample was irradiated at a fixed incident angle on the order of $0.12^{\circ}$ through a Huber diffractometer with X-ray energy of $12.398 \mathrm{keV}$ (X-ray wavelength $\lambda=0.10002 \mathrm{~nm}$ ), and the GIWAXS patterns were recorded with a 2D image detector (Pilatus $300 \mathrm{~K}$ ) with the sample-to-detector distances of $173.8 \mathrm{~mm}$.

OPV Device Fabrication. OPV devices were prepared on patterned indium tin oxide (ITO) substrates which were cleaned by ultra-sonication in deionized water, $\mathrm{CHCl}_{3}$, acetone, and tetramethylammonium hydroxide aqueous solution for $15 \mathrm{~min}$ each, and then deionized water for 25 min, followed by 2-propanol and ethanol for $15 \mathrm{~min}$ each. They were subsequently dried under nitrogen flow, and treated in a UV-ozone cleaner for $25 \mathrm{~min}$. A solution of $\mathrm{Zn}(\mathrm{OAc})_{2} \cdot 2 \mathrm{H}_{2} \mathrm{O}(67 \mathrm{mg})$, 2-methoxyethanol $(1 \mathrm{~mL})$, ethanolamine $(18.7 \mu \mathrm{L})$ stirred at room temperature, and was spin-coated on substrates at $3000 \mathrm{rpm}$ for $20 \mathrm{~s}$. The $\mathrm{ZnO}$ layer was dried at $200{ }^{\circ} \mathrm{C}$ for $30 \mathrm{~min}$, and then transferred into a glove box filled with dried $\mathrm{N}_{2}$ gas to coat the active layer. A photoactive layer of J71:NTTIC$\mathrm{X}(\mathrm{X}=\mathrm{H}, \mathrm{F}, \mathrm{Cl})$ was fabricated according to the following procedure. A blend solution of $\mathrm{J} 71$ and NTTIC-X with a polymer concentration of $11.4 \mathrm{mg} \mathrm{mL}^{-1}$ (1:0.9 ratio by weight) in chloroform was prepared in the presence of 1-chloronaphthalene $(0.5$ vol.\%) as a solvent additive and stirred on a hotplate at $25^{\circ} \mathrm{C} 400 \mathrm{rpm}$ for $3 \mathrm{~h}$. The active layer was spin-coated at $1000 \mathrm{rpm}$ for $20 \mathrm{~s}$ on the top of the $\mathrm{ZnO}$ layer, and the samples were annealed at $110^{\circ} \mathrm{C}$ for $10 \mathrm{~min}$. The thickness of the photoactive layer was ca. $100 \mathrm{~nm}$. All samples were finally transferred to an evaporation chamber for $\mathrm{MoO}_{3}$ deposition $(\sim 10 \mathrm{~nm})$ at a rate of $0.4-0.5 \AA \mathrm{s}^{-1}$ and $\mathrm{Ag}$ deposition $(\sim 100 \mathrm{~nm})$ at a rate of $1-2 \AA \mathrm{s}^{-1}$ before extracting their $J-V$ characteristics (under AM1.5 conditions).

\section{Synthetic Procedures}

Materials. NTTCHO ${ }^{2}$ 5,6-difluoro-1,1-dicyanomethylene-3-indanone (IC-F), ${ }^{3}$ 5,6-dichloro-1,1dicyanomethylene-3-indanone (IC-Cl), ${ }^{4}$ and NTTIC $^{2}$ were synthesized according to the reported procedures. J71 was purchased from 1-Material. All other chemicals were purchased from commercial supplier and used without further purification. 


\section{Synthesis.}

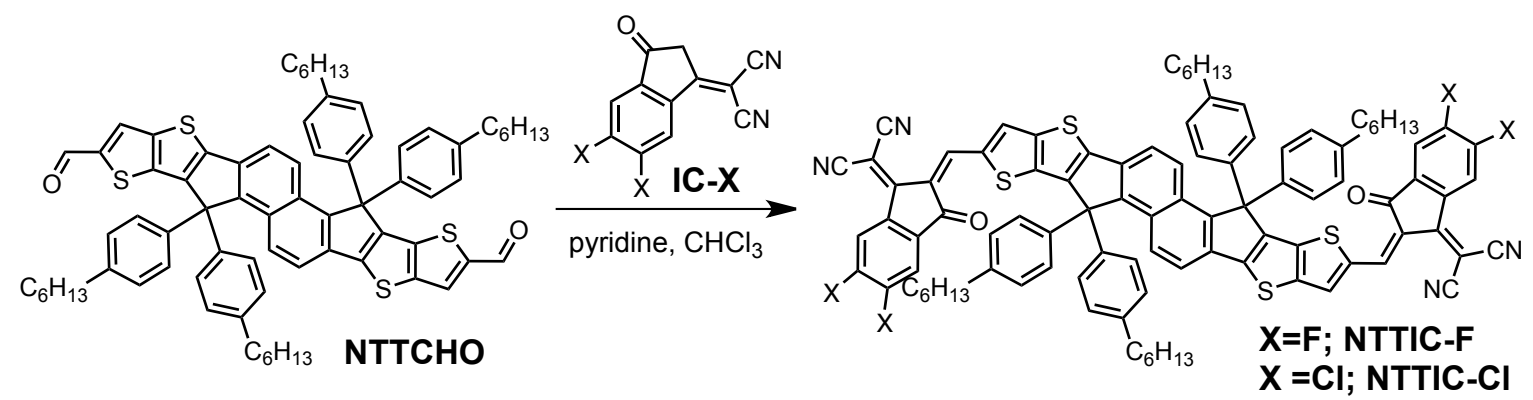

NTTIC-F. A solution of NTTCHO (103 mg, $0.0911 \mathrm{mmol}, 1.0$ equiv.) and 5,6-difluoro-1,1dicyanomethylene-3-indanone (IC-F, $104 \mathrm{mg}, 0.453 \mathrm{mmol}, 5.0$ equiv.) in $\mathrm{CHCl}_{3}(24 \mathrm{~mL})$ was deoxygenated with Ar for $30 \mathrm{~min}$. After 5 drops of pyridine were added, the reaction was stirred at reflux for 2 days. The crude product was reprecipitated with $\mathrm{CHCl}_{3} / \mathrm{EtOH}$, and the resulting residue was purified by column chromatography with hexane $/ \mathrm{CHCl}_{3}=1: 2$ as eluent, reprecipitated with $\mathrm{CHCl}_{3} / \mathrm{EtOH}$ again. NTTIC-F was obtained as a dark blue solid (127 mg, yield: $\left.90.2 \%\right) .{ }^{1} \mathrm{H}$ NMR (400 MHz, $\left.\mathrm{CDCl}_{3}, \mathrm{ppm}\right): \delta 8.81(\mathrm{~s}, 2 \mathrm{H}), 8.52(\mathrm{dd}, J=6.4,10.4 \mathrm{~Hz}, 2 \mathrm{H}), 8.21(\mathrm{~s}, 2 \mathrm{H}), 8.03(\mathrm{~d}, J=8.8$ $\mathrm{Hz}, 2 \mathrm{H}), 7.69$ (t, $J=7.2 \mathrm{~Hz}, 2 \mathrm{H}), 7.61(\mathrm{~d}, J=8.4 \mathrm{~Hz}, 2 \mathrm{H}), 7.28(\mathrm{~d}, J=8.0 \mathrm{~Hz}, 8 \mathrm{H}), 7.12(\mathrm{~d}, J=8.4$ $\mathrm{Hz}, 8 \mathrm{H}), 2.54(\mathrm{t}, J=8.0 \mathrm{~Hz}, 8 \mathrm{H}), 1.61-1.53(\mathrm{~m}, 4 \mathrm{H}), 1.34-1.22(\mathrm{~m}, 24 \mathrm{H}), 0.83(\mathrm{t}, J=6.8 \mathrm{~Hz}, 12 \mathrm{H})$. ${ }^{13} \mathrm{C} \mathrm{NMR}$ (100 MHz, $\left.\mathrm{CDCl}_{3}, \mathrm{ppm}\right): \delta 185.88,158.39,154.07,152.47,150.63,147.39,143.87,142.61$, $138.86,138.59,137.71,136.15,134.92,129.96,128.92,128.84,127.70,121.55,119.79,114.97$, 114.42, 114.30, 112.85, 69.71, 64.75, 35.69, 31.81, 31.26, 29.29, 22.70, 14.20. HRMS (p MALDI) calcd for $\left[\mathrm{C}_{98} \mathrm{H}_{80} \mathrm{~F}_{4} \mathrm{~N}_{4} \mathrm{O}_{2} \mathrm{~S}_{4}\right]^{+}:$1548.5095; found: 1548.5095. IR (ATR, $\mathrm{cm}^{-1}$ ): $v_{\max } 2935,2854,2363$, 2160, 1701, 1540, 1491, 1453, 1394, 1339, 1277, 1229, 1134, 1097, 912, 891, 818, 671. Melting point: $>300^{\circ} \mathrm{C}$.

NTTIC-Cl. A solution of NTTCHO (49.4 mg, $0.0439 \mathrm{mmol}, 1.0$ equiv.) and 5,6-dichloro-1,1dicyanomethylene-3-indanone (IC-Cl, $58.6 \mathrm{mg}, 0.224 \mathrm{mmol}, 5.0$ equiv.) in $\mathrm{CHCl}_{3}(12 \mathrm{~mL})$ was deoxygenated with Ar for $40 \mathrm{~min}$. After pyridine $(0.15 \mathrm{~mL})$ were added, the reaction was stirred at reflux for $36 \mathrm{~h}$. It was quenched with $\mathrm{H}_{2} \mathrm{O}$. The resulting residue was purified by column chromatography with hexane/ $\mathrm{CHCl}_{3}=1: 2$ as eluent, reprecipitated with $\mathrm{CHCl}_{3} / \mathrm{MeOH}$. NTTIC-Cl was obtained as a dark blue solid (57.1 mg, yield: 80.7\%). ${ }^{1} \mathrm{H}$ NMR (400 MHz, $\left.\mathrm{CDCl}_{3}, \mathrm{ppm}\right): \delta 8.82$ 
(s, 2H), $8.74(\mathrm{~s}, 2 \mathrm{H}), 8.19(\mathrm{~s}, 2 \mathrm{H}), 8.02(\mathrm{~d}, J=8.8 \mathrm{~Hz}, 2 \mathrm{H}), 7.95(\mathrm{~s}, 2 \mathrm{H}), 7.60(\mathrm{~d}, J=8.8 \mathrm{~Hz}, 2 \mathrm{H})$, $7.26(\mathrm{~d}, J=8.0 \mathrm{~Hz}, 8 \mathrm{H}), 7.11(\mathrm{~d}, J=8.4 \mathrm{~Hz}, 8 \mathrm{H}), 2.53(\mathrm{t}, J=8.8 \mathrm{~Hz}, 8 \mathrm{H}), 1.32-1.25(\mathrm{~m}, 24 \mathrm{H}), 0.82$ $(\mathrm{t}, J=6.8 \mathrm{~Hz}, 12 \mathrm{H}) .{ }^{13} \mathrm{C} \mathrm{NMR}\left(100 \mathrm{MHz}, \mathrm{CDCl}_{3}, \mathrm{ppm}\right): \delta 185.93,158.29,154.31,152.52,150.64$, $143.96,142.57,139.78,139.47,139.11,138.72,137.78,136.05,134.89,129.94,128.85,128.77$, $128.52,127.69,127.02,125.25,121.52,119.74,114.34,69.73,35.63,31.74,31.19,29.78,29.23$, 22.78, 22.64, 14.14. HRMS (p MALDI) calcd for $\left[\mathrm{C}_{98} \mathrm{H}_{80} \mathrm{~F}_{4} \mathrm{~N}_{4} \mathrm{O}_{2} \mathrm{~S}_{4}\right]^{+}:$: 1548.5095; found: 1548.5095 . IR (ATR, $\left.\mathrm{cm}^{-1}\right): v_{\max } 2921,2850,2218,1702,1570,1539,1458,1442,1390,1276,1240,1218,1135$, 1014, 913, 899, 836, 817, 783, 670, 610. Melting point: $>300^{\circ} \mathrm{C}$. 
Table S1. HOMO/LUMO Energy Levels and Electron Mobilities $\left(\mu_{\mathrm{e}}\right)^{a}$ of NTTIC-F, NTTIC-Cl, and NTTIC Films.

\begin{tabular}{cccccc}
\hline NFA & $\begin{array}{c}\mathrm{HOMO}^{b} \\
/ \mathrm{eV}\end{array}$ & $\begin{array}{c}\mathrm{LUMO}^{c} \\
/ \mathrm{eV}\end{array}$ & $\begin{array}{c}\mathrm{HOMO}^{d} \\
/ \mathrm{eV}\end{array}$ & $\begin{array}{c}\mathrm{LUMO}^{d} \\
/ \mathrm{eV}\end{array}$ & $\begin{array}{c}\mu_{\mathrm{e}} / 10^{-4} \\
\mathrm{~cm}^{2} \mathrm{~V}^{-1} \mathrm{~s}^{-1}\end{array}$ \\
\hline NTTIC-F & -5.85 & -4.23 & -5.53 & -3.43 & 4.3 \\
NTTIC-Cl & -5.87 & -4.28 & -5.58 & -3.51 & 5.4 \\
NTTIC & -5.68 & -3.96 & -5.46 & -3.39 & 4.6
\end{tabular}

${ }^{a}$ Measured by SCLC with the device configuration of ITO/ZnO/NFA/Al. ${ }^{b}$ Determined by PYSA. ${ }^{c}$ Determined by HOMO + optical bandgap in the film states. ${ }^{d}$ Calculated from DFT.

Table S2 Singlet Exciton Lifetimes Obtained by Fitting Photoluminescence Decays of NTTICF, NTTIC-CI, NTTIC, and ITIC in Chloroform Solutions and Films. ${ }^{a}$

\begin{tabular}{|c|c|c|c|}
\hline sample & $\tau_{1} / \mathrm{ps}$ & $\tau_{2} / \mathrm{ps}$ & $\tau_{3} / \mathrm{ps}$ \\
\hline NTTIC-F solution & $400(0.999)$ & $8500(0.001)$ & - \\
\hline NTTIC-F film ${ }^{b}$ & $140(0.71)$ & $360(0.26)$ & $1900(0.03)$ \\
\hline NTTIC-Cl solution & $470(0.98)$ & $1000(0.02)$ & - \\
\hline NTTIC-Cl film ${ }^{b}$ & $160(0.79)$ & $420(0.18)$ & $1700(0.03)$ \\
\hline NTTIC solution & $220(0.99)$ & $1100(0.01)$ & - \\
\hline NTTIC film ${ }^{b}$ & $120(0.85)$ & $320(0.13)$ & $1600(0.02)$ \\
\hline ITIC solution & $200(0.96)$ & $500(0.04)$ & - \\
\hline ITIC film $^{b}$ & $100(0.69)$ & $190(0.30)$ & $950(0.01)$ \\
\hline
\end{tabular}

${ }^{a}$ Data in parantheses are component ratios. ${ }^{b}$ Average photoluminescence lifetimes of the NTTIC-F, NTTIC-Cl, NTTIC, and ITIC films are 250, 250, 180, and $140 \mathrm{ps,} \mathrm{respectively.}$ 

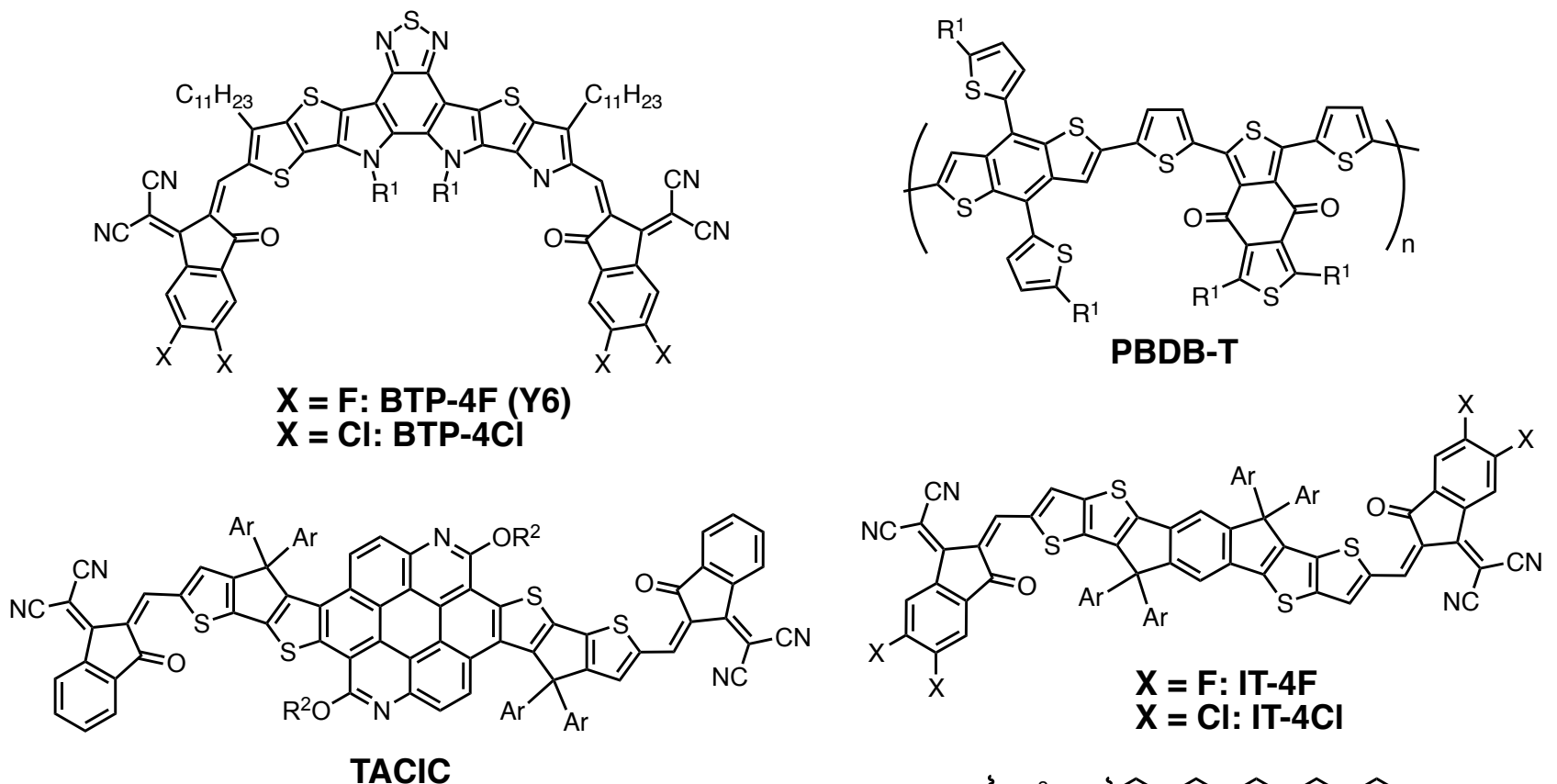

$$
\xi-\mathrm{Ar}=\xi-\mathrm{C}_{6} \mathrm{H}_{13}
$$

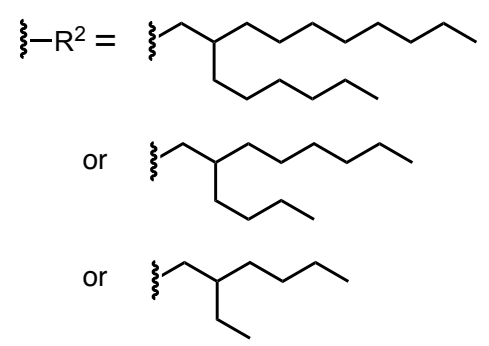

Figure S1. Chemical structures of NFAs and PBDB-T. 
(a)
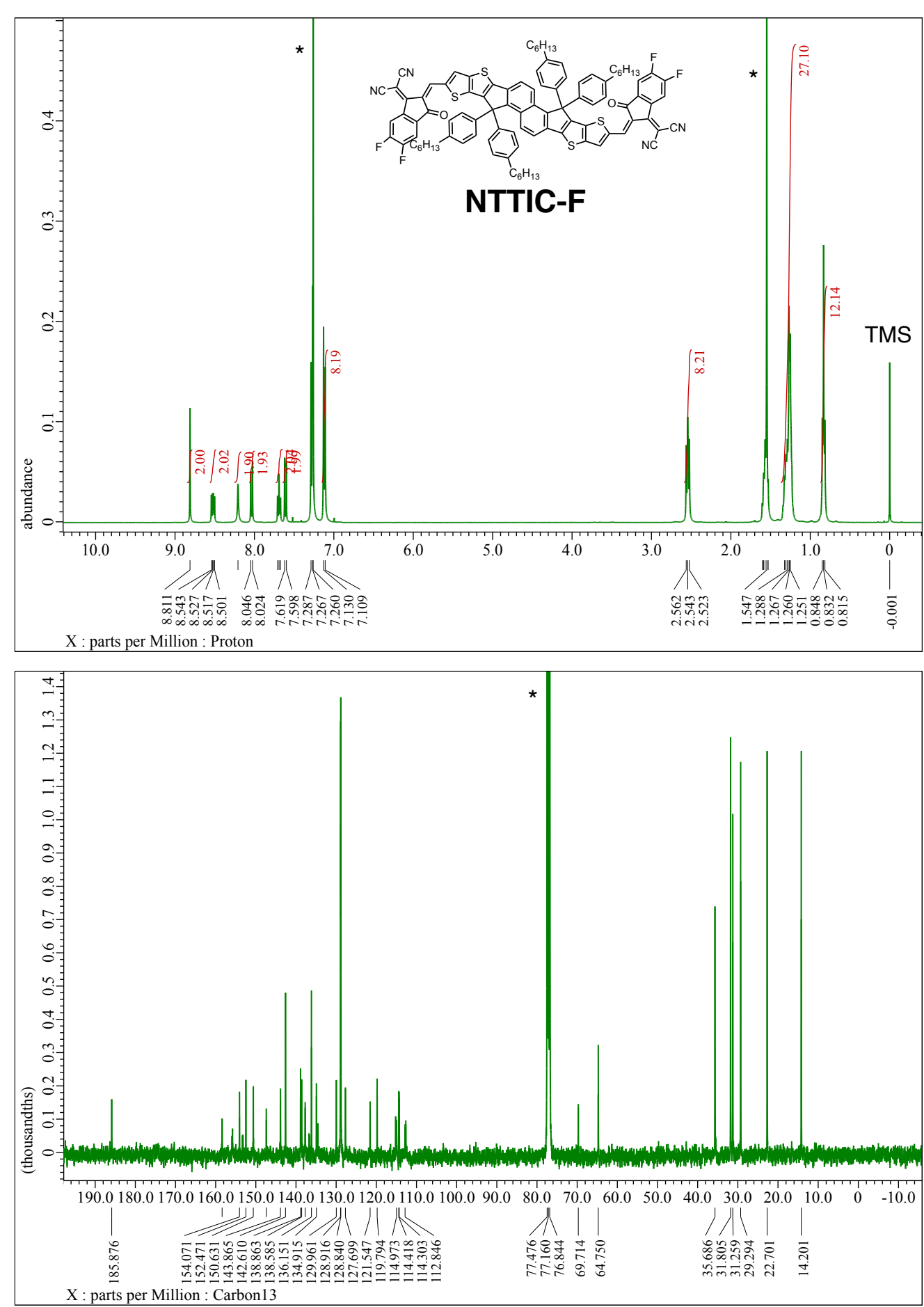
(b)
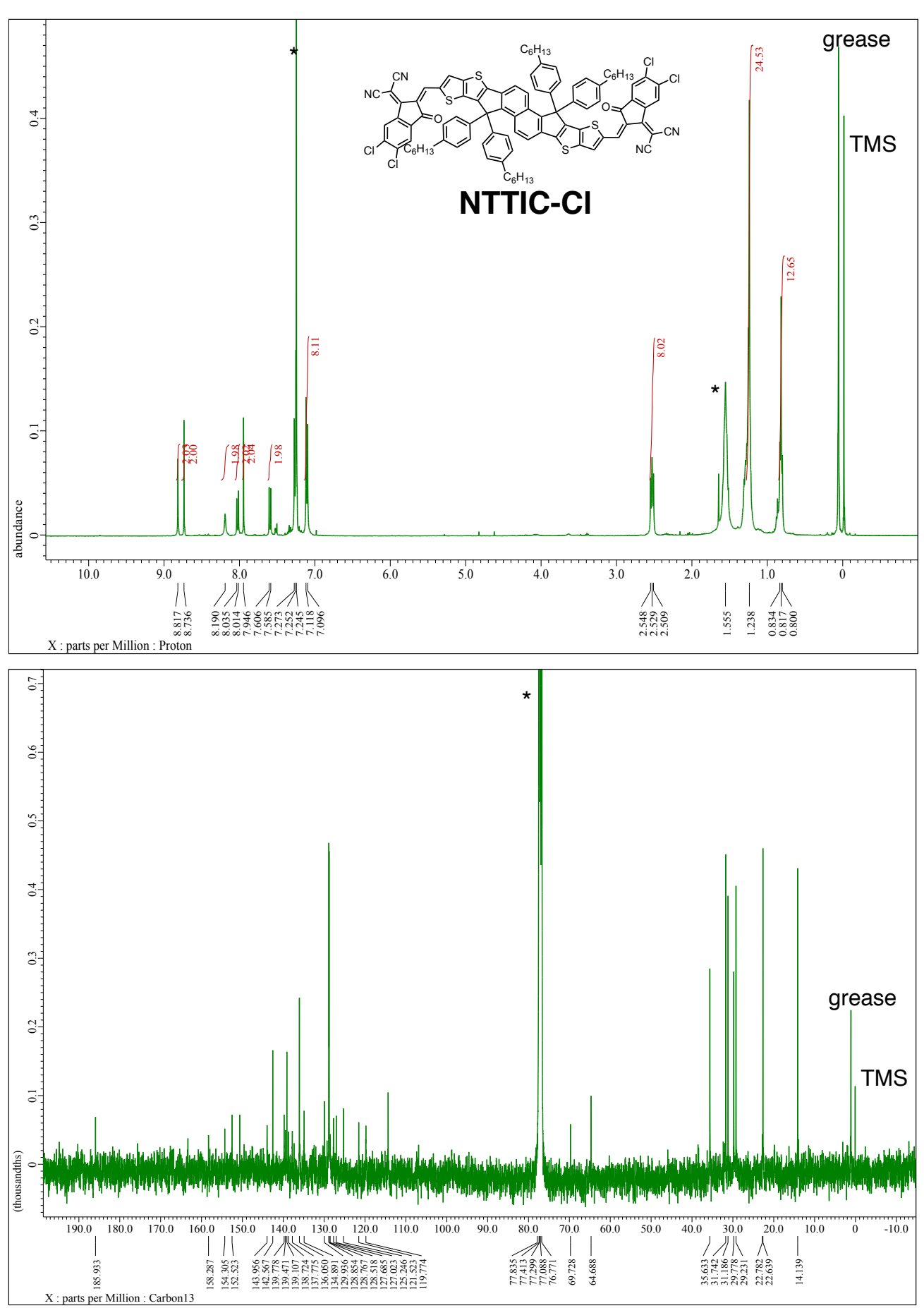

Figure S2. ${ }^{1} \mathrm{H}$ (upper) and ${ }^{13} \mathrm{C}$ (lower) NMR spectra of (a) NTTIC-F and (b) NTTIC-Cl in $\mathrm{CDCl}_{3}$. Peaks marked with $*$ arise from residual solvents or impurities. 
(a)

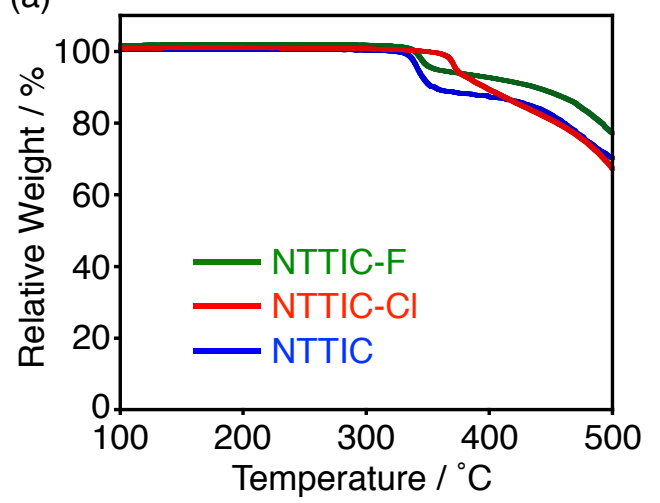

(c)

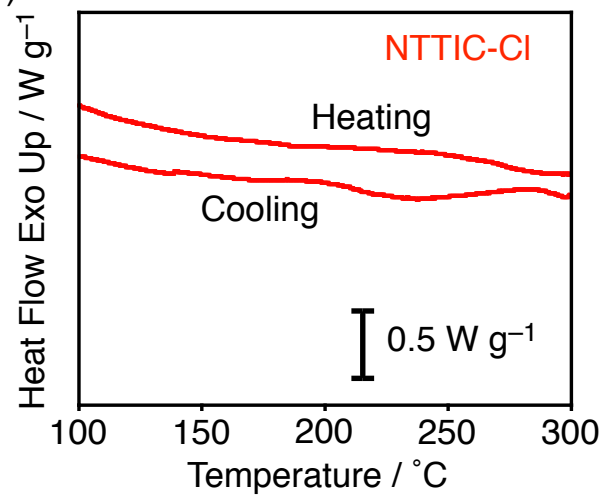

(b)

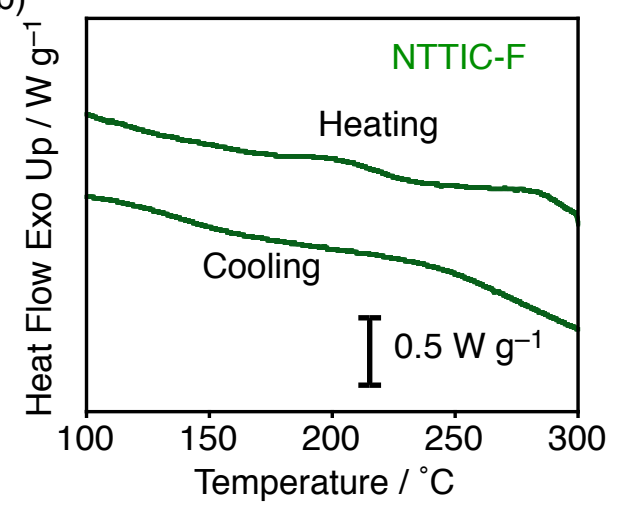

(d)

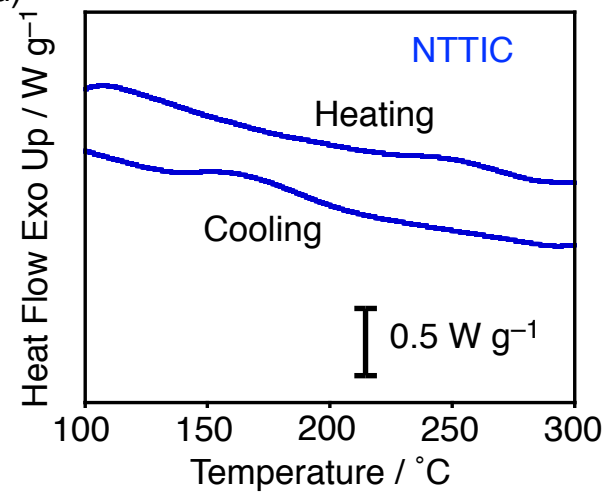

Figure S3. (a) TGA curves of NTTIC-F, NTTIC-Cl, and NTTIC. DSC curves of (b) NTTIC-F, (c) NTTIC-Cl, and (d) NTTIC. The analyses were performed under flowing nitrogen at a scan rate of $10{ }^{\circ} \mathrm{C} \mathrm{min}^{-1}$. The decomposition temperatures (5\% weight loss) of NTTIC-F, NTTIC-Cl, and NTTIC were 357,373 , and $343{ }^{\circ} \mathrm{C}$, respectively. 

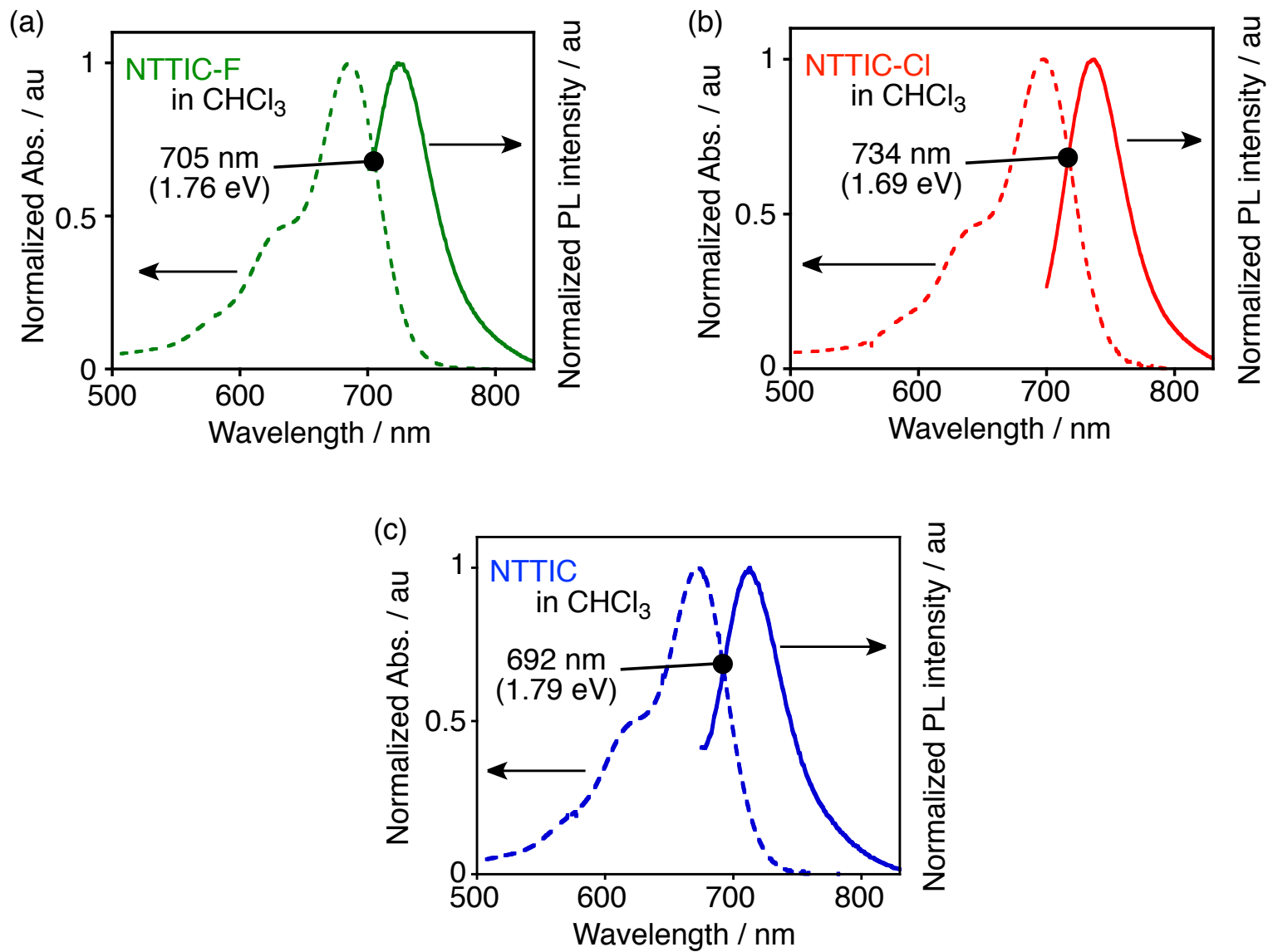

Figure S4. Normalized vis-NIR absorption and photoluminescence (PL) spectra of (a) NTTIC-F, (b) NTTIC-Cl, and (c) NTTIC in chloroform. The excitation wavelengths for photoluminescence measurements are the absorption maxima. The wavelengths and energies at the intersection points are shown in the figures. 
(a)

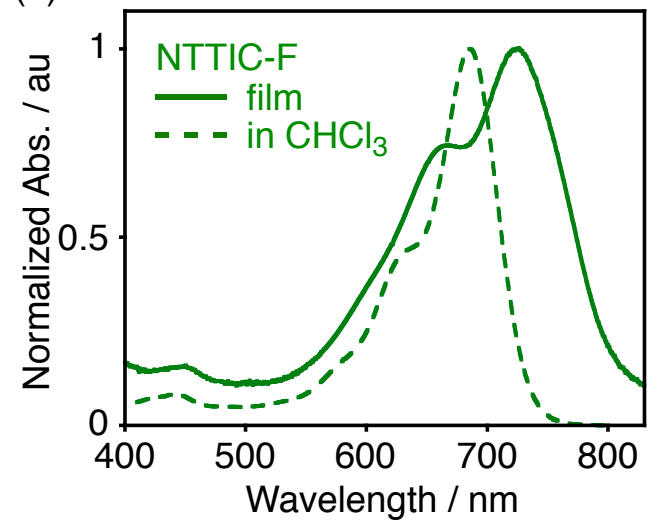

(b)

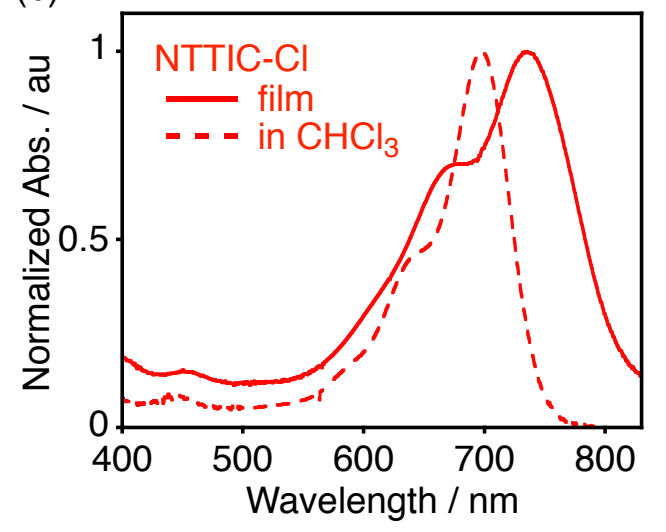

(b)

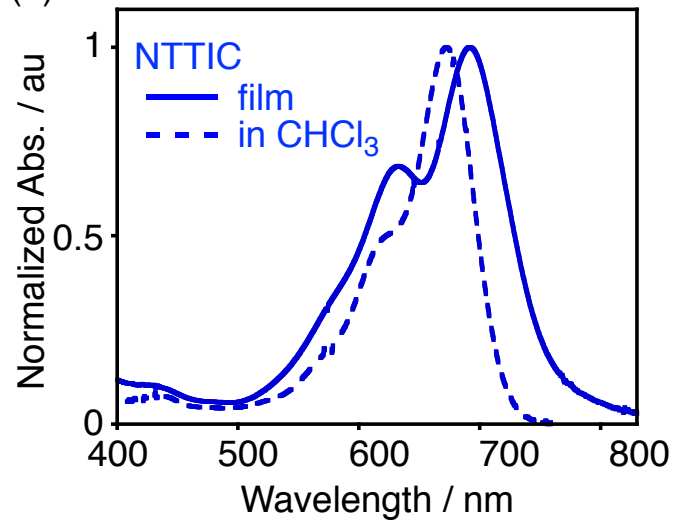

Figure S5. Normalized UV-vis-NIR absorption spectra of (a) NTTIC-F, (b) NTTIC-Cl, and (c) NTTIC films and chloroform solutions. 

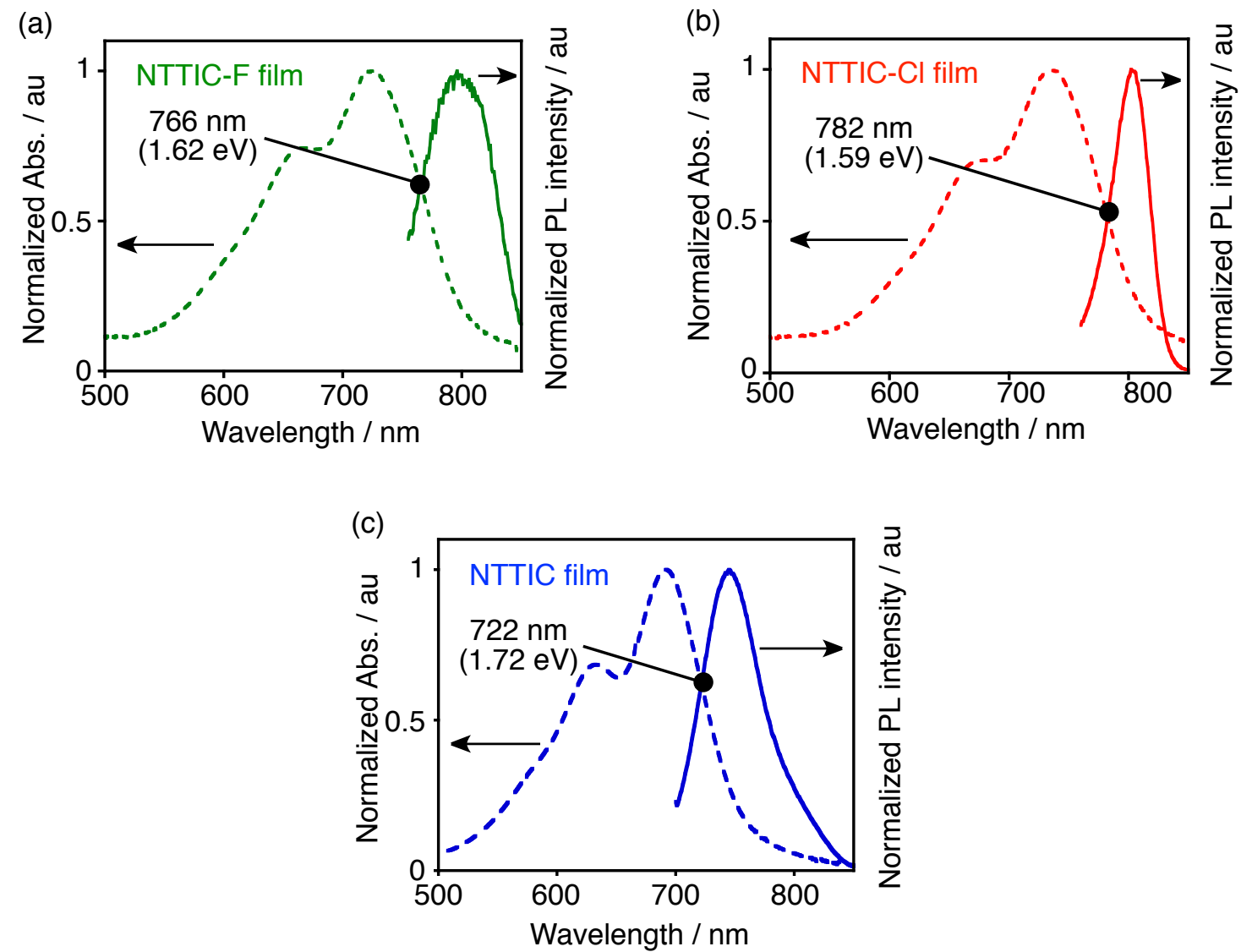

Figure S6. Normalized UV-vis-NIR absorption and photoluminescence (PL) spectra of (a) NTTICF, (b) NTTIC-Cl, and (c) NTTIC films. The excitation wavelengths for fluorescence measurements are the absorption maxima. The wavelengths and energies at the intersection points are shown in figures. 
(a)

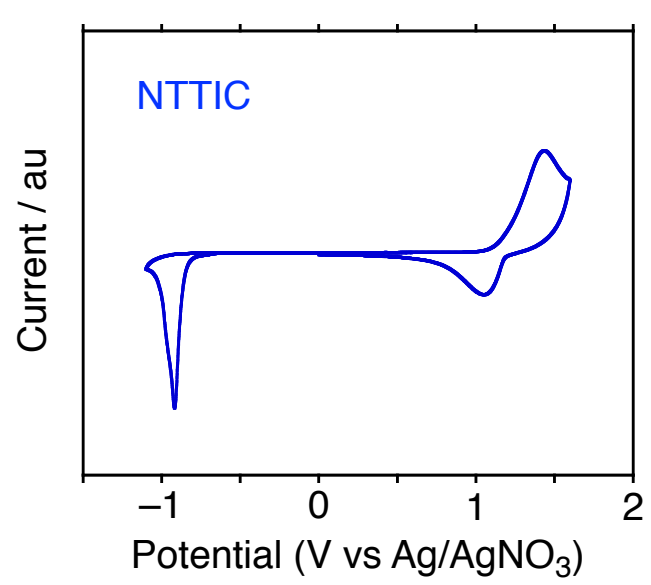

(c)

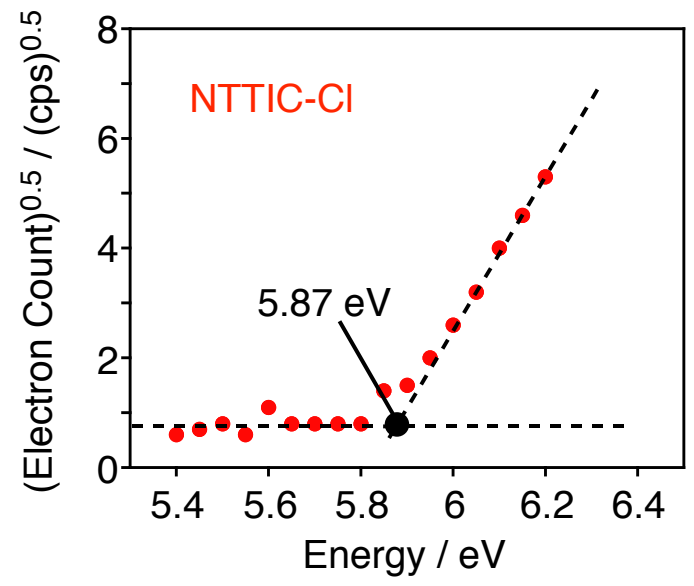

(b)

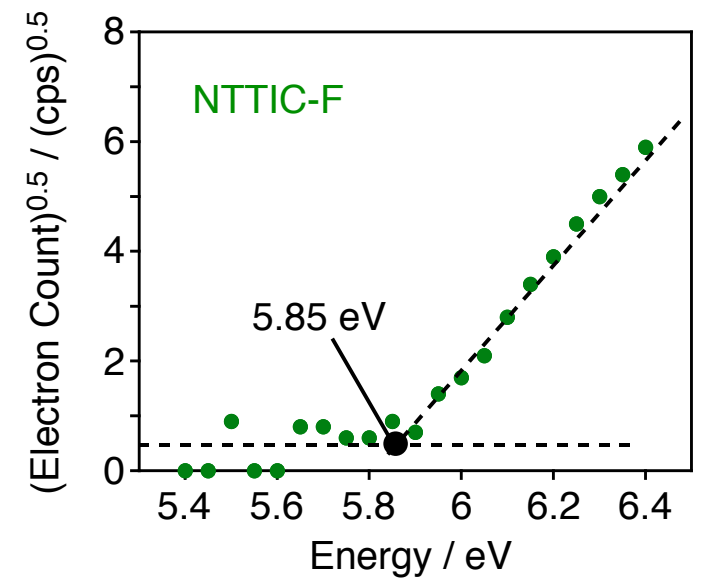

(d)

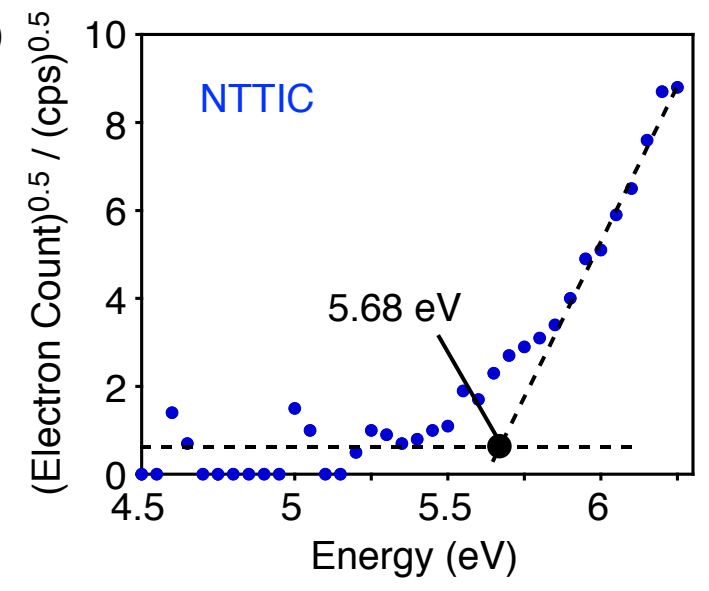

Figure S7. (a) Cyclic voltammogram of NTTIC film and photoemission yield spectroscopy in air (PYSA) of (b) NTTIC-F, (c) NTTIC-Cl, and (d) NTTIC films. 

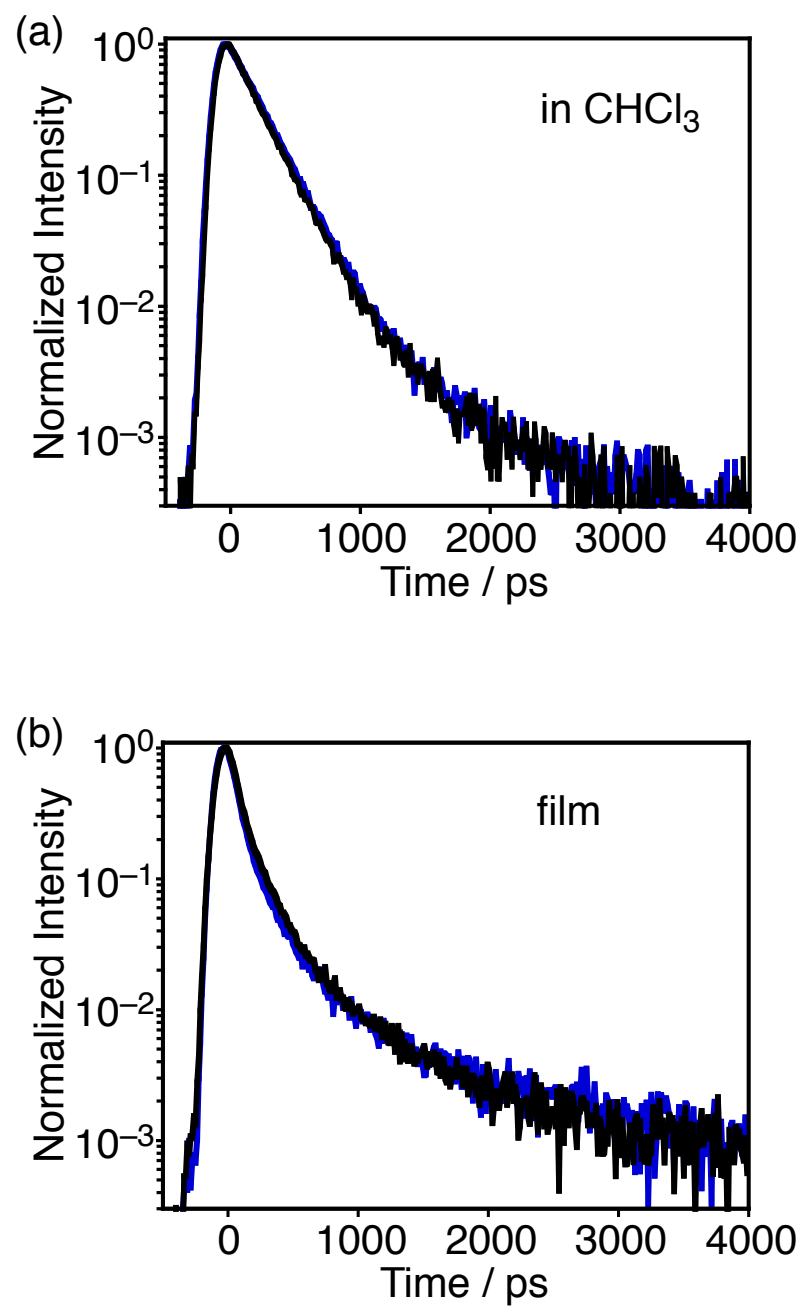

Figure S8. Photoluminescence decays of (a) NTTIC in chloroform and (b) NTTIC film. The excitation intensities were $210 \mu \mathrm{J} \mathrm{cm}$ cm $^{-2}$ (blue line) and $105 \mu \mathrm{J} \mathrm{cm}^{-2}$ (black line). The photoluminescence decay rates in both (a) and (b) are independent of the excitation light intensities, suggesting that the influence of the bimolecular deactivation processes of singlet excitons, such as singlet-singlet exciton annihilation, can be excluded. 

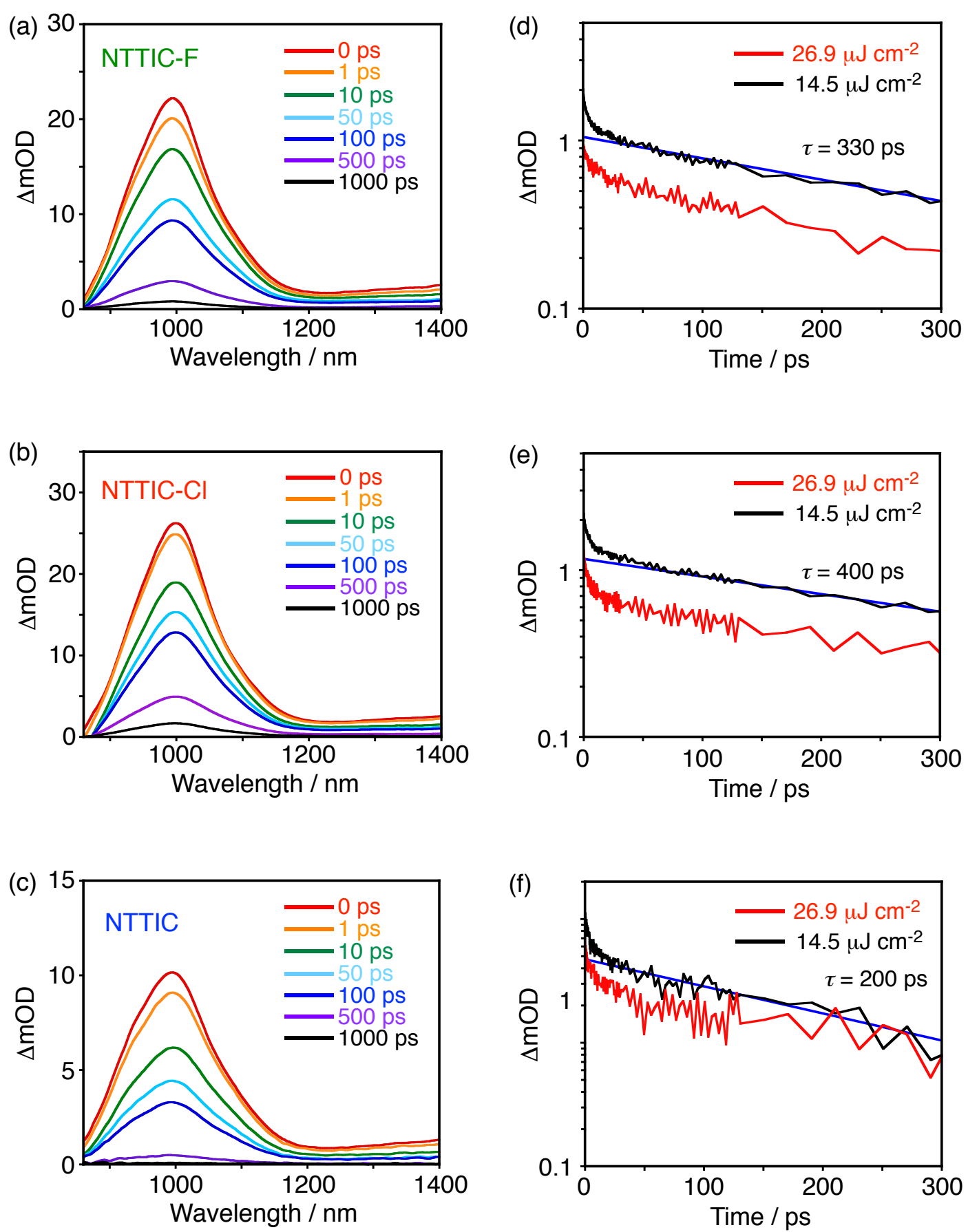

Figure S9. (a-c) Femtosecond to picosecond transient absorption spectra of (a) NTTIC-F, (b) NTTIC$\mathrm{Cl}$, and (c) NTTIC in chloroform. The excitation wavelength and intensity were $700 \mathrm{~nm}$ and $26.9 \mu \mathrm{J}$ $\mathrm{cm}^{-2}$, respectively. (d-f) Transient absorption decay profile of (d) NTTIC-F, (e) NTTIC-Cl, and (f) NTTIC in chloroform at $1300 \mathrm{~nm}$ and its fitting (black line). The decay fitting and the lifetime are also shown. 

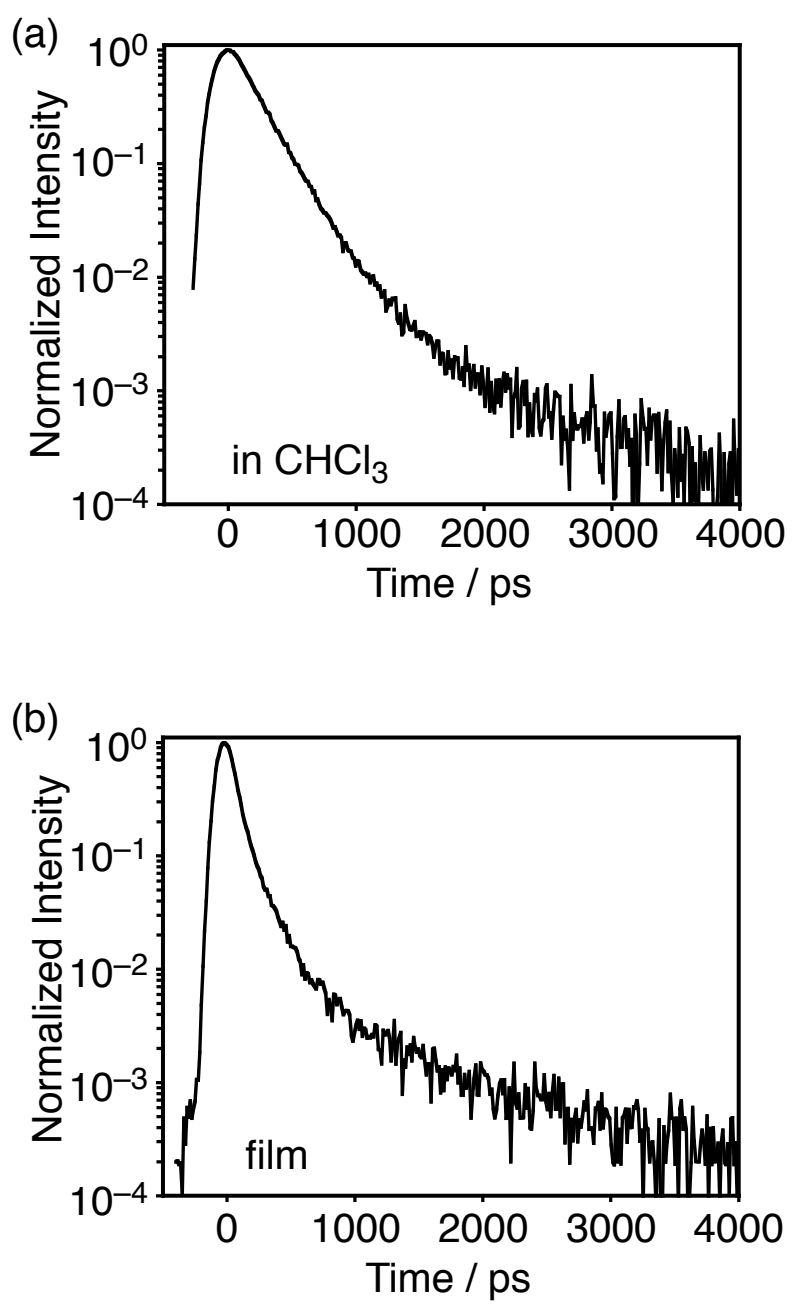

Figure S10. Photoluminescence decay of ITIC in (a) chloroform and (b) film. The samples were excited at the absorption maxima. The emissions were detected at the maximum wavelengths. 
(a)

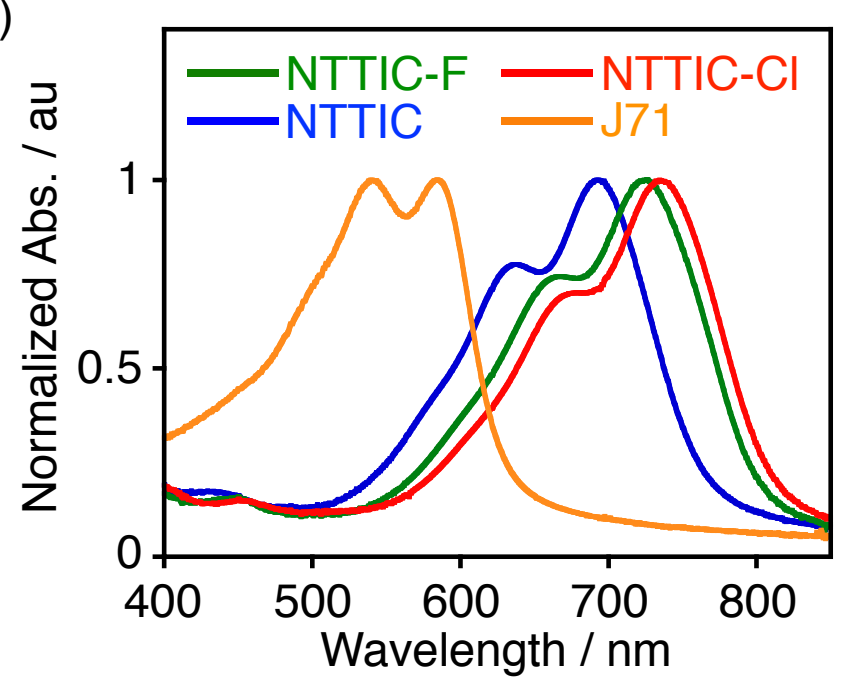

(b)

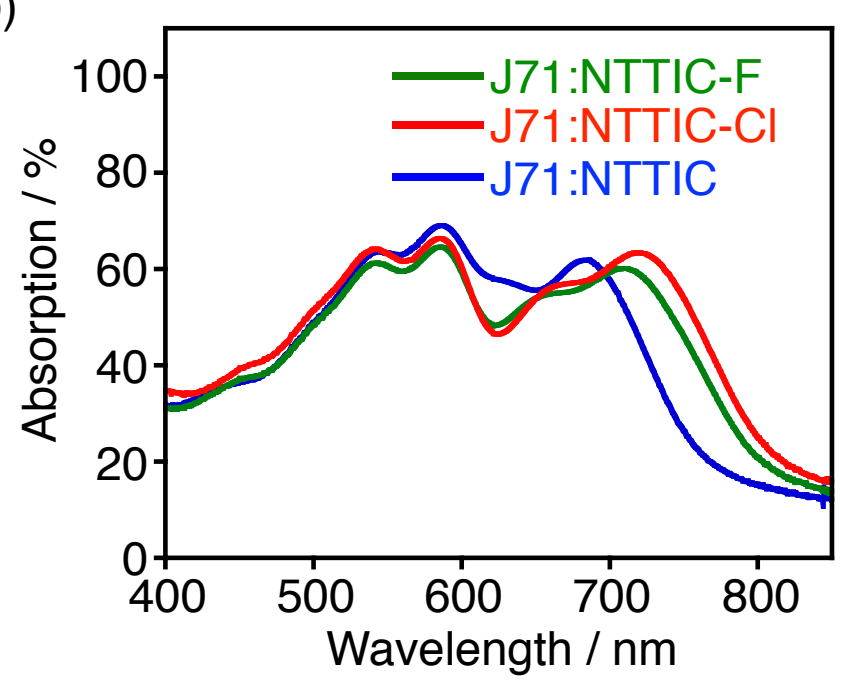

Figure S11. (a) Normalized UV-vis-NIR absorption spectra of NTTIC-F, NTTIC-Cl, NTTIC and J71 neat films. (b) UV-vis-NIR absorption spectra of J71:NTTIC-F, J71:NTTIC-Cl, and J71:NTTIC on ITO/ZnO substrates. Note here that the total absorption of the ITO/ZnO/J71:NFA/ $/ \mathrm{MoO}_{3} / \mathrm{Ag}$ devices are higher than the values in (b) due to the reflection from the Ag electrode in real devices. 
(a)

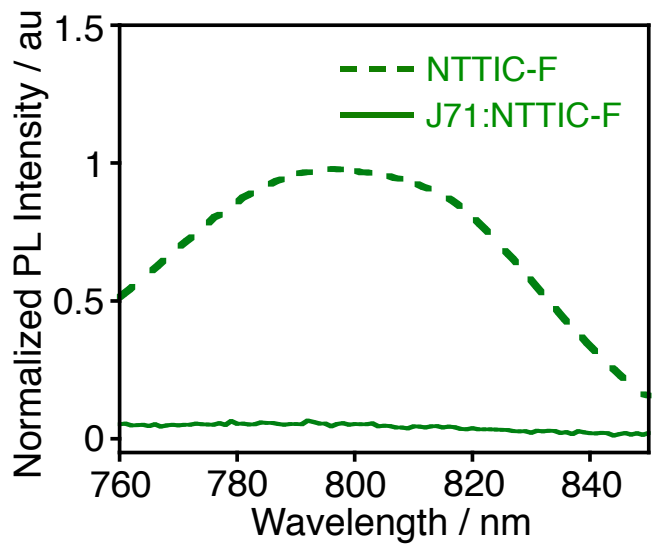

(c)

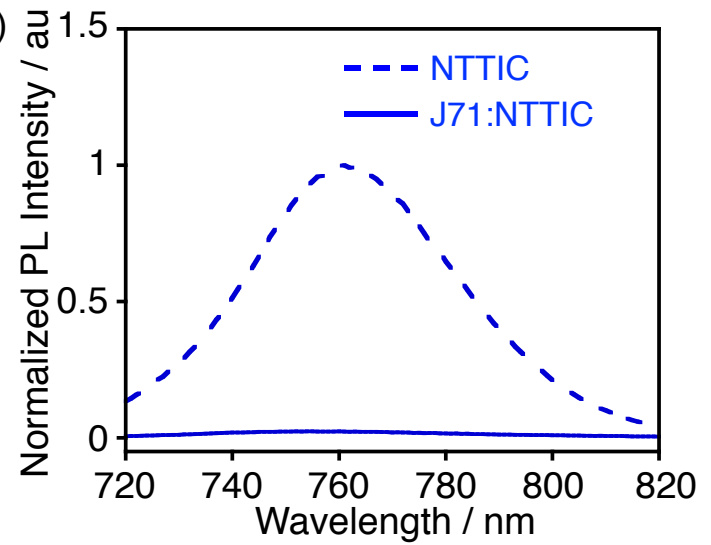

(b)

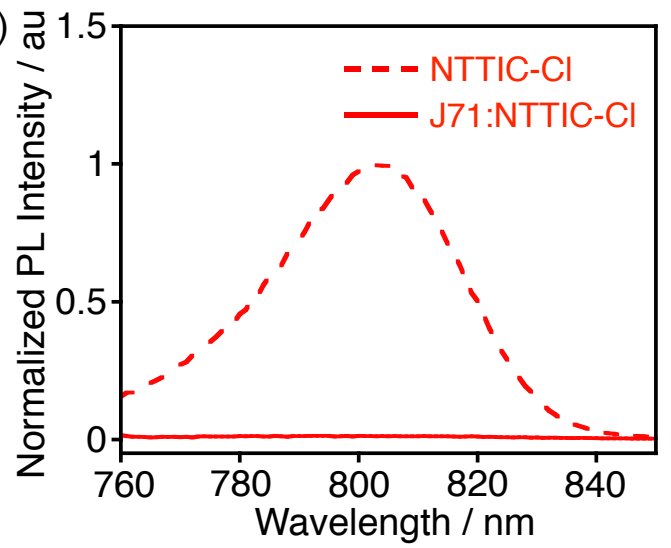

(d)

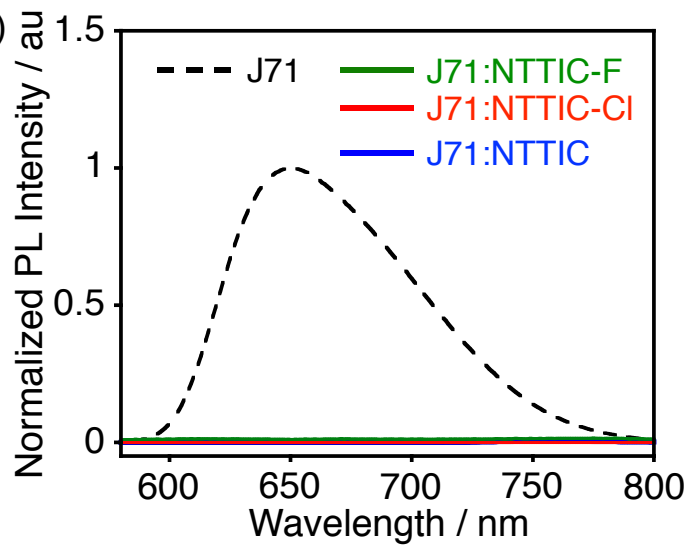

Figure S12. (a-c) Photoluminescence spectra of (a) NTTIC-F single component film (green dotted) and J71:NTTIC-F (green solid), (b) NTTIC-Cl single component film (red dotted) and J71:NTTIC$\mathrm{Cl}$ (red solid), and (c) NTTIC single component film (blue dotted) and J71:NTTIC-F (blue solid). The samples were excited at 724, 736, and $692 \mathrm{~nm}$, respectively, where the NFAs were predominantly excited. The emission intensities are normalized by that of the acceptor single component film considering the difference in the absorbances of the J71:NFA films at the excitation wavelength. (d) Photoluminescence spectra of J71 single component film (black dotted) and blend films of J71 with NTTIC-F (green solid), NTTIC-Cl (red solid), and NTTIC (blue solid). The excitation wavelength was $500 \mathrm{~nm}$ where $\mathrm{J} 71$ was predominantly excited. The emission intensities are normalized by that of the J71 single component film considering the difference in the absorbances of the J71:NFA films at the excitation wavelength. 
(a) J71:NTTIC-F

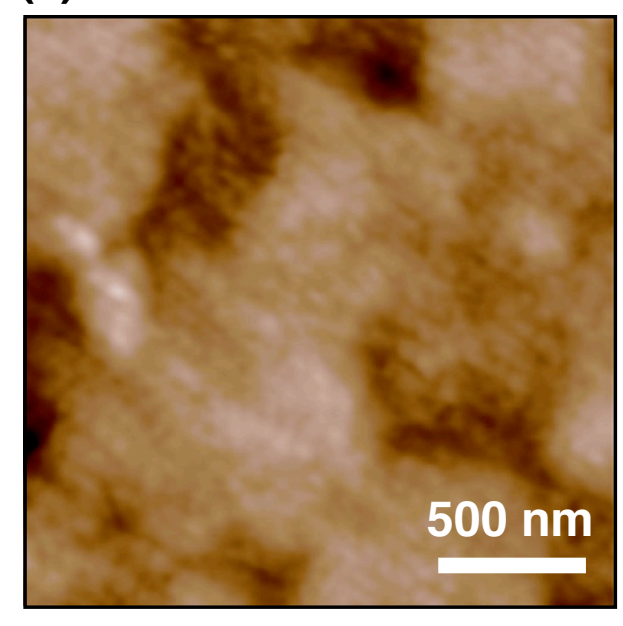

(b) J71:NTTIC-CI

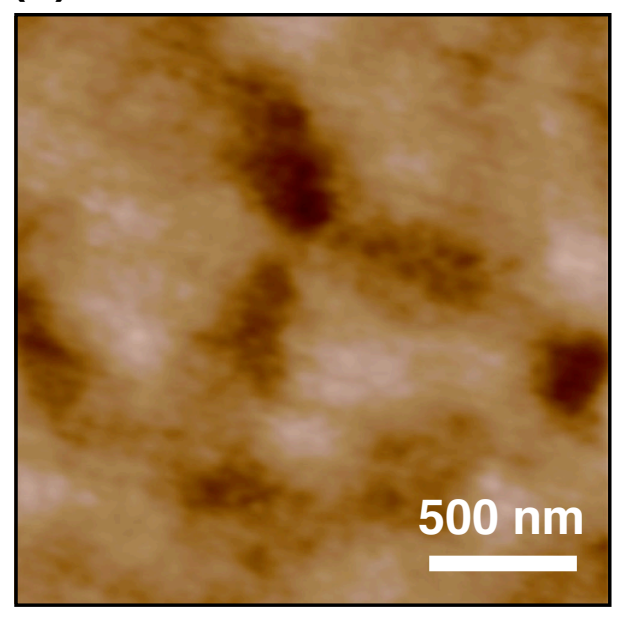

\section{(b) J71:NTTIC}

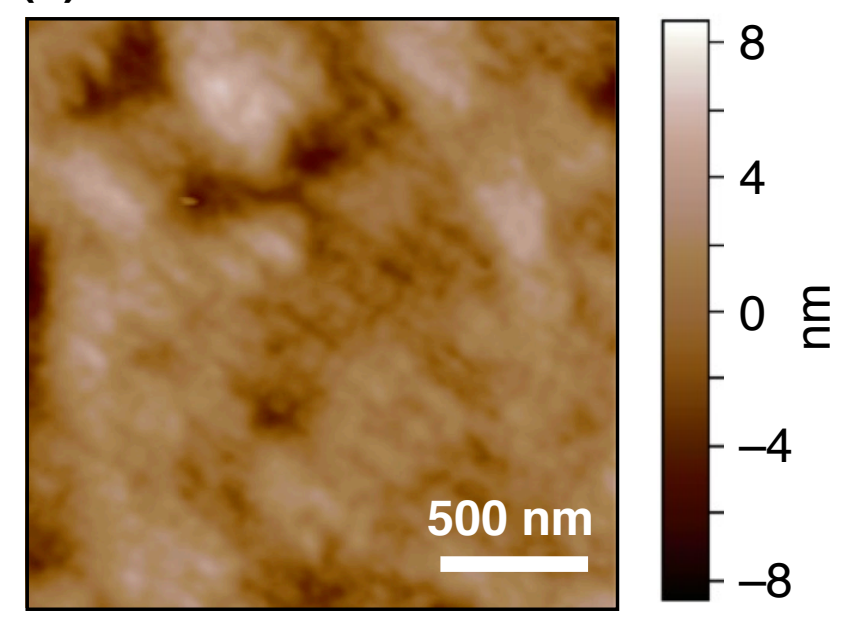

Figure S13. AFM images of (a) J71:NTTIC-F, (b) J71:NTTIC-Cl, and (c) J71:NTTIC on ITO/ZnO substrates. The color scale represents the height topography, with bright and dark representing the highest and lowest features, respectively. The root-mean-square (rms) surface roughnesses are (a) 1.8, (b) 1.8 , and (c) $2.2 \mathrm{~nm}$. 

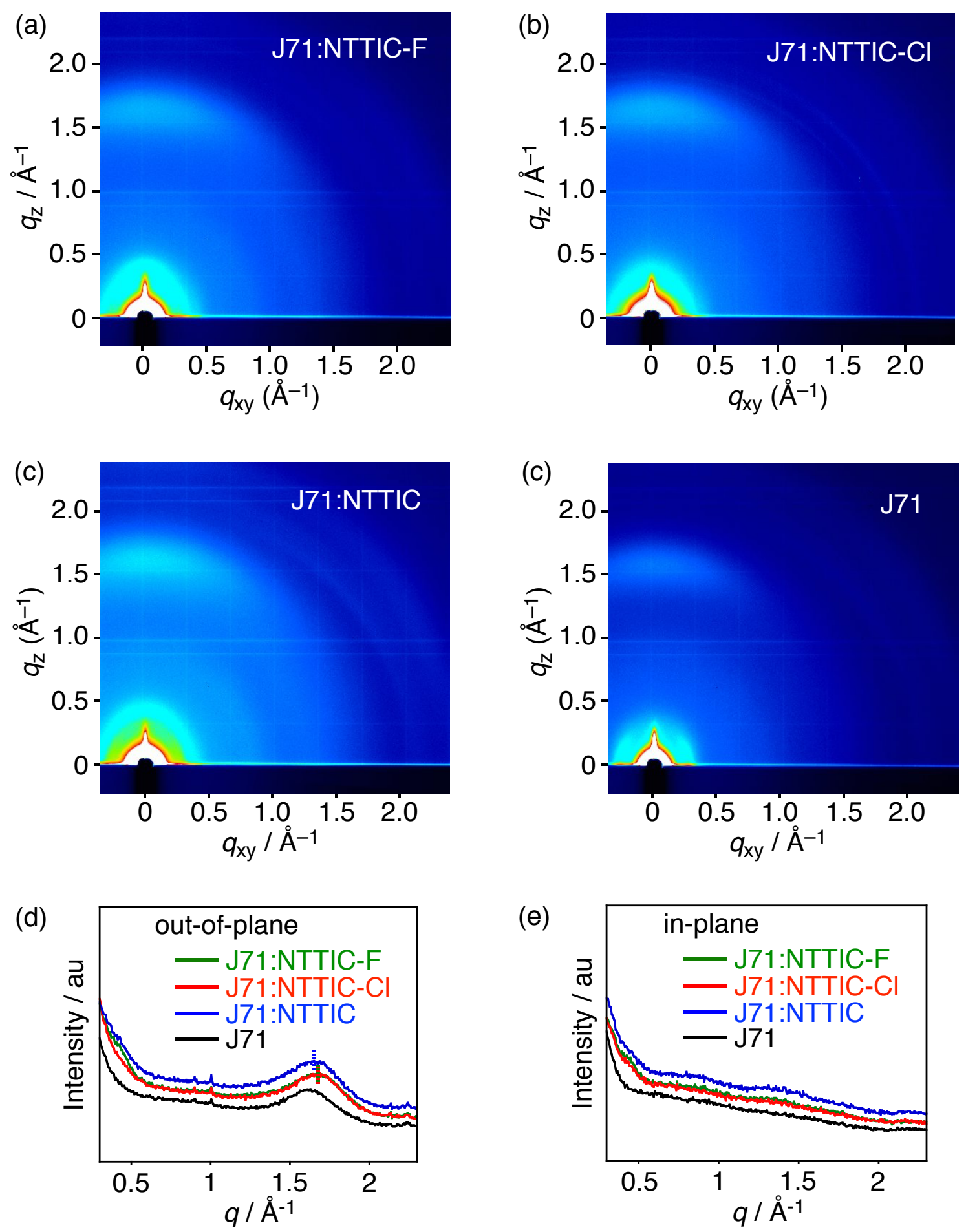

Figure S14. Two dimensional GIWAXS plots of (a) J71:NTTIC-F, (b) J71:NTTIC-Cl, (c) J71:NTTIC, and (d) J71 films on ITO/ZnO substrates. (e) Out-of-plane and (f) in-plane GIWAXS profiles. Peak positions of (010) reflections of NFAs are marked with dotted line in (d). 

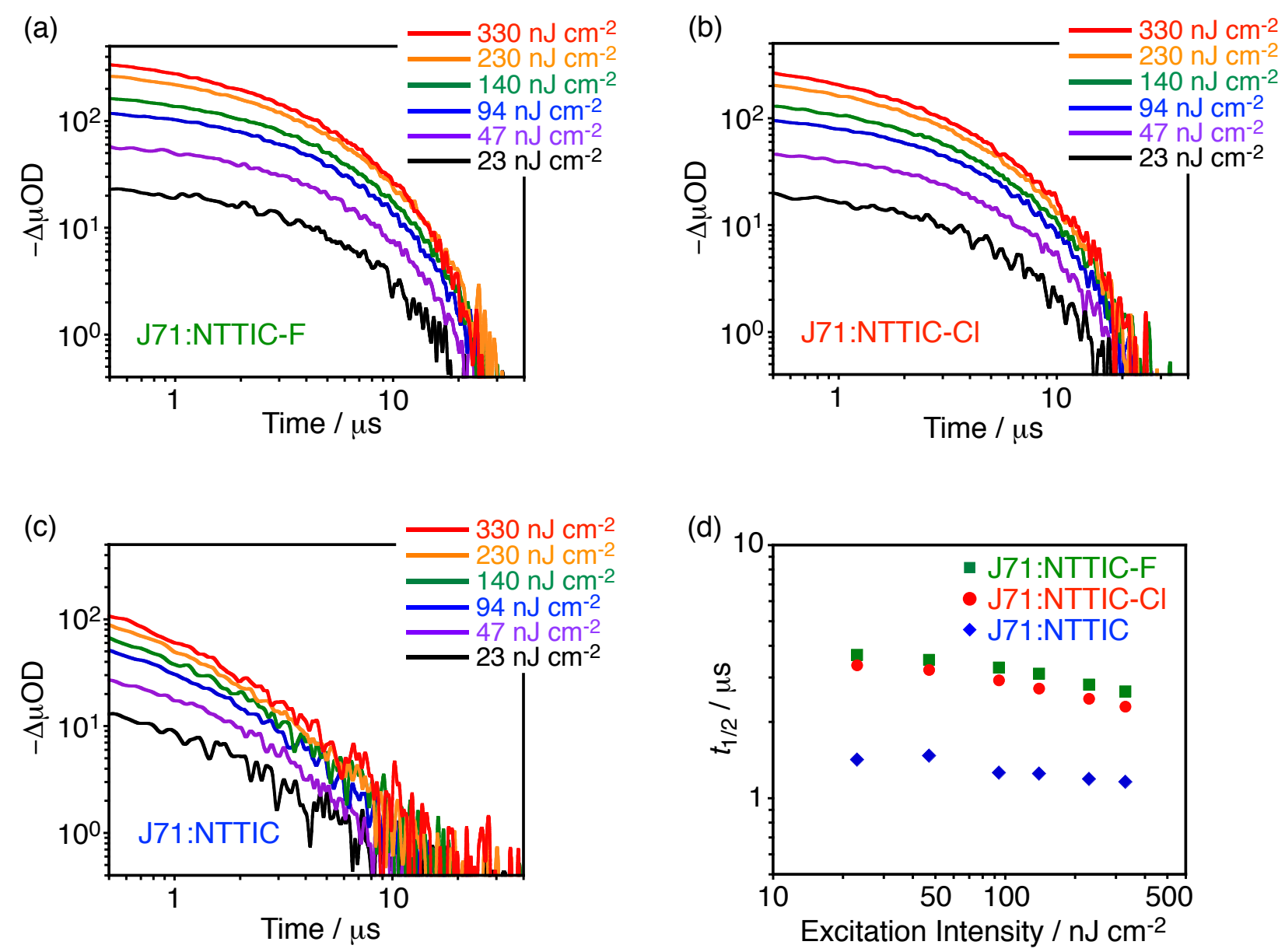

Figure S15. Microsecond transient absorption decay profiles of (a) J71:NTTIC-F, (b) J71NTTIC-Cl, and (c) J71:NTTIC at $600 \mathrm{~nm}$ with various excitation intensities. The excitation wavelength was 532 nm. (d) Excitation intensity dependence of half-life $\left(t_{1 / 2}\right)$ of the ground state bleaching (GSB) of J71 monitored at $600 \mathrm{~nm}$. The J71:NTTIC-F, J71NTTIC-Cl, and J71:NTTIC blend films were excited at $532 \mathrm{~nm}$ with various excitation intensities. The GSB intensity at $0.5 \mu$ s was set as the initial signal intensity. 


\section{References}

(1) Gaussian 09, Revision D.01, Frisch, M. J.; Trucks, G. W.; Schlegel, H. B.; Scuseria, G. E.; Robb, M. A.; Cheeseman, J. R.; Scalmani, G.; Barone, V.; Mennucci, B.; Petersson, G. A.; Nakatsuji, H.; Caricato, M.; Li, X.; Hratchian, H. P.; Izmaylov, A. F.; Bloino, J.; Zheng, G.; Sonnenberg, J. L.; Hada, M.; Ehara, M.; Toyota, K.; Fukuda, R.; Hasegawa, J.; Ishida, M.; Nakajima, T.; Honda, Y.; Kitao, O.; Nakai, H.; Vreven, T.; Montgomery, J. A. Jr.; Peralta, J. E.; Ogliaro, F.; Bearpark, M.; Heyd, J. J.; Brothers, E.; Kudin, K. N.; Staroverov, V. N.; Keith, T.; Kobayashi, R.; Normand, J.; Raghavachari, K.; Rendell, A.; Burant, J. C.; Iyengar, S. S.; Tomasi, J.; Cossi, M.; Rega, N.; Millam, J. M.; Klene, M.; Knox, J. E.; Cross, J. B.; Bakken, V.; Adamo, C.; Jaramillo, J.; Gomperts, R.; Stratmann, R. E.; Yazyev, O.; Austin, A. J.; Cammi, R.; Pomelli, C.; Ochterski, J. W.; Martin, R. L.; Morokuma, K.; Zakrzewski, V. G.; Voth, G. A.; Salvador, P.; Dannenberg, J. J.; Dapprich, S.; Daniels, A. D.; Farkas, O.; Foresman, J. B.; Ortiz, J. V.; Cioslowski, J.; Fox, D. J.; Gaussian, Inc.; Wallingford CT, 2013.

(2) Umeyama, T.; Igarashi, K.; Tamai, Y.; Wada, T.; Takeyama, T.; Sasada, D.; Ishida, K.; Koganezawa, T.; Ohtani, S.; Tanaka, K.; Ohkita, H.; Imahori, H. Prolongation of the Singlet Exciton Lifetime of Nonfullerene Acceptor Films by the Replacement of the Central Benzene Core with Naphthalene. Sustain. Energy Fuels 2021, 5, 2028-2035.

(3) Cui, Y.; Ren, H.; Yu, J.; Wang, Z.; Qian, G. An Indanone-Based Alkoxysilane Dye with Second Order Nonlinear Optical Properties. Dyes Pigm. 2009, 81, 53-57.

(4) Cui, Y.; Yang, C.; Yao, H.; Zhu, J.; Wang, Y.; Jia, G.; Gao, F.; Hou, J. Efficient Semitransparent Organic Solar Cells with Tunable Color Enabled by an Ultralow-Bandgap Nonfullerene Acceptor. Adv. Mater. 2017, 29, 1703080. 